\title{
Kalça protezi ameliyatı sonrası normal hayata dönüş
}

\author{
Return to normal life after hip prosthesis surgery
}

\author{
Ender Kaya
}

SBÜ Prof. Dr. Cemil Taşçıoğlu Şehir Hastanesi, Psikiyatri Kliniği, İstanbul

\begin{abstract}
Kalça kırığı sonrası hastaların yalnızca \%50-60'ının kendi evlerine dönebildiği, taburculuk sonrası 1 yıl içinde \%20-90'ında yeni yetersizlikler oluştuğu ve \%15-25'inin 1 yıl içinde yaşamını kaybettiği belirlenmiştir. Kalça kırı̆̆ı sonrası uygulanan tedavi ve bakımın odak noktası, hastaların kırık öncesi işlevsel düzeye ulaşmasını sağlamaktır. Bu hastalar, en iyi koşullarda bile yaşa ve kırığa bağlı komplikasyonlardan dolayı yüksek risk altındadır. Kalça kırığı ameliyatı sonrasında bireysel tedavi ve bakım girişimlerinin planlanması, rehabilitasyon gereksiniminin belirlenmesi, olası komplikasyonların önlenmesi yaşam kalitesi açısından önemli görünmektedir.
\end{abstract}

Anahtar sözcükler: kalça protezi; rehabilitasyon; yaşam kalitesi
It has been determined that only $50-60 \%$ of the patients can return to their own homes after a hip fracture, $20-90 \%$ of them have new deficiencies within 1 year after discharge and $15-25 \%$ of them die within 1 year. The focus of treatment and care after hip fracture is to ensure that patients reach a functional level before the fracture. These patients are at high risk for complications related to age and fracture, even in the best of circumstances. Planning individual treatment and care interventions after hip fracture surgery, determining the need for rehabilitation, and preventing possible complications seem important in terms of quality of life.

Key words: hip replacement; rehabilitation; quality of life
K alça protezi ameliyatı, kalça ekleminde ileri derecede hasar olduğunda ağrının azaltılması, fonksiyonel bağımsızlığın kazandırılması ve yaşam kalitesinin artırılması amacıyla uygulanan cerrahi bir girişim olup, "kalça replasmanı" ya da "kalça artroplastisi" olarak da adlandırılmaktadır. ${ }^{[1,2]}$

Kalça protezi ameliyatı sonrası hastaların günlük yaşam aktivitelerini etkileyen, yaşam kalitelerinde azalmaya neden olan pek çok sorunla karşılaşması, bu hastalara verilecek bakımın planlanarak sürekliliğinin sağlanmasını, hasta ve hasta yakınlarının taburculuğa hazırlanmalarını ve evde bakıma yönelik eğitilmelerini gerektirmektedir. ${ }^{[3]}$ Rehabilitasyonun başlıca amacı ağrıyı azaltmak, eklem hareket açıklığını ve kas kuvvetini artırarak fiziksel fonksiyonları iyileştirmek, günlük yaşam aktivitelerine katılımı artırmak, yürüme paternini düzenlemek ve yaşam kalitesini artırmaktır. ${ }^{[4]}$ Cerrahi sonrası sürecin başarısı doktor, hemşire, fizyoterapist, sosyal hizmet uzmanı ve diğer sağlık profesyonellerinden oluşan çok alanlı ekip çalışması ile sağlanır. ${ }^{[5]}$
Hastanede kaldıkları süre içerisinde sağlık ekibi üyelerinin gözetiminde ve rehberliğinde olan hastalar, taburcu olduktan sonra günlük yaşam aktivitelerini nasıl sürdüreceklerini ve günlük yaşama nasıl uyum sağlayacaklarını bilmek isteyeceklerinden hastaneden taburcu olmadan önce hastaya ve evdeki bakımında yardımcı olacak kişiye; evdeki yaşamın bağımsız ve güvenli bir biçimde sürdürülmesine, yani kalça eklemini koruyarak günlük yaşam aktivitelerini yerine getirmelerine yönelik taburculuk öncesi evde bakım eğitimi verilmelidir. ${ }^{[6]}$

Kalça protezi ameliyatı sonrası hastaların günlük yaşam aktivitelerini yerine getirmede güçlük yaşaması, hastaların bakımlarında bu yönden desteklenmelerini gerektirmektedir. Bireyin yaşamı boyunca yerine getirdiği yaşamsal aktiviteleri içeren ve hastalara bu doğrultuda bakım verilmesini ele alan hemşirelik modellerinden biri Roper, Logan ve Tierney tarafindan geliştirilen Günlük Yaşam Aktiviteleri Bakım Modeli (GYABM)'dir. ${ }^{[7]}$

- Illetişim adresi: Uzm. Dr. Ender Kaya, SBÜ Prof. Dr. Cemil Taşçıoğlu Şehir Hastanesi, Psikiyatri Kliniği, Darülaceze Caddesi No:27 Okmeydanı, Şişli, İstanbul Tel: 0533 - 7104870 E-posta: enderkaya76@yahoo.com

- Geliş tarihi: 9 Ocak2021 Kabul tarihi: 8 Şubat 2021 
Kalça protezi ameliyatı sonrası yapılan iyi bir taburculuk planlaması, hasta ve yakınlarının evdeki bakımlarına yönelik eğitimini, evde izleminin sağlanmasını ve destek alınacak hizmetlerinin koordinasyonunu gerektirmektedir. Hastaların evde bakımına yönelik eğitim, ameliyat öncesi dönemden itibaren başlayan planlı bir süreç olup, hasta ve yakınlarına gereksinimleri doğrultusunda yapılacak ameliyat, ağrı kontrolü, verilecek bakım, uygulanacak diyet, yara bakımı, kullanılacak ilaçlar, egzersizler, günlük yaşamda dikkat edilecekler, gelişebilecek komplikasyonların belirti ve bulguları ile bunların önlenmesine yönelik alınması gereken önlemler, evde yapılacak düzenlemeler, doktor kontrolleri ve evde izlemlerle ilgili bilgi ve uygulamaları kapsamaktadır. ${ }^{[8]}$

\section{Kalça protezi ameliyatı sonrası hastaların normal hayata dönmeleri için özellikle şu hususlara dikkat edilmelidir.}

\section{Ev Düzenlemeleri}

Hasta ve yakınları evde meydana gelebilecek kazaların önlenmesi, evin daha rahat kullanılabilmesi için yapılabilecek düzenlemeler ve güvenlik önlemleri konularında bilgilendirilmelidir. Kişilerin cerrahi sonrası evde güvenliklerinin sağlanabilmesi ve hareket alanının artırılması için ev içi düzenlemeler önerilmektedir. Zemininde takılıp düşmeye neden olabilecek halılar, paspaslar kaldırılmalı, banyo ve tuvaletlerin zeminine kaymayan paspas konulmalıdır. Mobilyalar düzenlenerek yürüteç veya bastonla yürümek için yeterli alan oluşturulmalı, evcil hayvan varsa altı hafta süreyle evden uzaklaştırılmalıdır. ${ }^{[9,10]}$

\section{Iletişim}

Kalça protez ameliyatı sonrası hastalarda depresyon, işitme güçlügüü, bilinç değiş̧ikliği, yalnızlık, sosyal izolasyon, psikolojik sıkıntı ve yorgunluk nedeniyle sözlü/sözsüz iletişimde azalma görülebilir. ${ }^{[1]}$

\section{Kişisel Temizlik ve Giyim}

Giyinme aktiviteleri sırasında önlem protokollerinde anlatılan kalça pozisyonlarına 6-8 hafta dikkat edilmeli, gerekli durumlarda yardım istenmelidir. Pantolon giyme aktivitesinde öne uzanması gereken durumlarda giyinme sopası kullanılarak önce ameliyatı bacak, sonra sağlam bacak giyilmelidir. Kalça protezi ameliyatlarından sonra ağrı, çıkık korkusu ve hareket kısıtılığı nedeniyle olumsuz etkilenilebilmektedir. Bu aktivite kapsamında hastalarda el-yüz ve ağız bakımını yapamama, vücut bakımını yapamama, perine bakımını yapamama ve kendi kendine giyinmede güçlük yaşanabilmektedir. ${ }^{[7]}$

\section{Boşaltım}

Mesane ve barsak fonksiyonlarının değerlendirilmesi ve sürdürülmesi yaşam için önemlidir. Kalça protezi ameliyatlarından sonra hastalar boşaltım aktivitesine ilişkin olarak üriner enfeksiyon, üriner retansiyon, idrar ve gaita kontrol yetisinin bozulması, ishal ve kabızlık sorunları yaşayabilirler. ${ }^{[12]}$

\section{Hareket}

Ameliyat sonrası kronik dönemde rehabilitasyonun amaçları arasında akut dönemde olduğu gibi çıkıktan korumak, günlük yaşam aktivitelerinde bağımsızlık sağlanması ve yaşam kalitesinin artırılması bulunmaktadır. Kronik dönemde hedefler, kas gücünü ve kitlesini artırmak, denge ve koordinasyonu geliştirmek, adaptif araçların etkin kullanımını sağlamak, yardımcı cihazlarla bağımsız transfer ve hareketin öğretilmesi, duruşun düzeltilmesi, şekil bozukluğunun engellemesi, eklem hareketliliği ve stabilitesinin sağlanması ve taburcu sonrası verilen ev programına devamın sağlanmasıdır. ${ }^{[13]}$ Fizyoterapist gözetimindeki rehabilitasyon programı yürüme hızı ve ahengini artırır. Yürüme hızı yaş, cinsiyet, ameliyat süresi, hastanede kalış süresi ve kas kuvveti ile ilişkilidir. Yapılan çalışmalarda egzersizin yürüme hızını artırdığı, dirençli egzersizlerin ise yürüme hızını dirençsiz uygulanan egzersizlere göre daha fazla artırdığı bulunmuştur. ${ }^{[14]}$

\section{Aktivite ve Spora Dönüş}

Kalça protezi kişinin rekreasyonel aktivitelerden ve spordan uzak kalmasına yol açmamalıdır. Bu hasta grubu düz zeminde yürüyüş, bisiklet, merdiven, yüzme, golf aktiviteleri gibi güvenli aktiviteleri seçmeli, yüksek şiddetli ve darbe riskinin olduğu futbol, basketbol, tenis, jogging gibi aktivitelerden uzak durmalıdır. ${ }^{[15]}$

\section{Çalışma ve Eğlenme}

Rehabilitasyonun bir parçası olan iş ve uğraşı tedavisi, kişilerin günlük yaşam aktivitelerini gerçekleştirmelerini kolaylaştırmak, var olan yetenekleri koruyup geliştirerek engellerin üstesinden gelmek ve mesleki performans kayıplarını en aza indirmekle ilgilenen tedavi yöntemidir. İş ve uğraşı tedavisinin temel amacı kişinin bireysel yetenekleri, mesleği ve çevresi arasındaki uyumu korumak, onarmak veya yeniden oluşturmaktır. ${ }^{[16]}$ İş ve uğraşı tedavisi, benimsediği bütünsel yaklaşım ile kişilerin fiziksel ve fonksiyonel iyileşmelerinin yanı sıra, yaralanma öncesi sosyal rollerine dönebilme, kendine güven ve benlik saygısını artırma, psikolojik ve duygusal durumda iyileşme sağlama, işe dönüşü ve çalışma ortamına uyumu kolaylaştırma, eğlence ve sağlık aktivitelerine katılım sağlamaya yönelik tavsiyeler verir. Böylece kişinin topluma katılımının ve yaşam kalitesinin artmasına yardımcı olur. ${ }^{[17]}$ 


\section{Cinsel Yaşam}

Cinselliğin ifade edilmesini içeren bir aktivitedir. Kalça protezi ameliyatlarından sonra oluşan hareket kısıtlılığı, ağrı ve çıkık korkusu cinsel yaşamı olumsuz etkileyebilmektedir. Hastalarda ameliyat sonrası cinsel yaşam konusunda bilgi eksikliği ve cinsel aktivitede zorlanma sorunları görülebilmektedir. Hastanın, cinsel ilişkiden 3-6 ay kadar uzak durması önerilmektedir. ${ }^{[18]}$

\section{Ruhsal Durum}

Her ne kadar eve dönüş pozitif bir gelişme olarak görülüyorsa da fiziksel bakımın sürekliliğiyle ilgili güçlükler ile görünüm, rol, işlev ve yaşam biçimindeki değişikliklerle ilgili çeşitli psikolojik sorunlarla baş etme çabası içinde olan birey ve aile oldukça zor bir dönem yaşayabilir. ${ }^{[19]}$ Kalça protezi ameliyatlarından sonra hastaların yaşadıkları sorunlar iyileşmelerine ilişkin kaygı duymalarına, ölüm korkusuna ya da ölümü kendilerine yakın hissetmelerine neden olabilmektedir. ${ }^{[7]}$ Bireyin günlük yaşamdaki stresten uzaklaşmasını, bedenen ve ruhen dinlenmesini sağlayan bir aktivitedir. Uyku, kalça protezi ameliyatlarından sonra ağrı, hareket kısıtlılığı, sürekli yatak istirahati, kullanılan ilaçlar ve ruhsal sorunlar nedeniyle olumsuz etkilenebilmektedir. ${ }^{[20]}$ Ameliyat sonrası kronik dönemde çeşitli psikolojik sorunlara da rastlanabilir. Bunlar arasında depresyon ve deliryum önde gelenlerdir. Bu tip problemler kırık öncesi ya da sonrası dönemde gözlenebilir. Öncesinde mevcut bir psikolojik sorunu ya da demansı olsun ya da olmasın bu hastalarda, dehidratasyon, hipotansiyon, cerrahi süreçte hipoksi, anestezi, ilaç zehirlenmeleri ve hareketsizliğin tetikleyebileceği deliryum açısından dikkatli olunmalıdır. ${ }^{[21]}$ Bu çerçevede kalça protezi operasyonu sonrası akut ve kronik dönemde hastanın ruhsal yönden değerlendirilmesi önemli görünmektedir.

Sonuç olarak, kalça protezi ameliyat sonrası doğru ve etkili rehabilitasyon programlarının uygulanması hastanın yaşam kalitesinin artmasında önemli yer tutmaktadır. Ameliyat sonrası aile desteğinin yanında hemşirelik bakımı, fizyoterapist desteği, sosyal hizmet ve ruhsal destek önem arz etmektedir.

\section{KAYNAKLAR}

1. Stomberg, MW, Öman, UB. Patients undergoing total hip arthroplasty: a perioperative pain experience. J Clin Nurs 2006;15(4):451-8. Crossref

2. Altıntaş F, Gökçe A, Yavuz U, Uğutmen, E. Total Eklem Protezi Ameliyatı Zayıflamayı Etkiler mi? Turkiye Klinikleri Tıp Bilimleri Derg 2008;28(3):287-90. https://www.turkiyeklinikleri.com/ article/en-total-eklem-protezi-ameliyati-zayiflamayi-etkilermi-50514.html

3. Louw A, Diener I, Butler DS, Puendetura EJ. Preoperative education addressing postoperative pain in total joint arthroplasty: Rewiev of content and educational delivery methods. Physiother Theory Prac 2013;29(3):94-175. Crossref
4. Bilik, Ö. Kalça Protezi Uygulanmış Olan Hastaların Evde Telefonla İlenmesinin İyileşmeye Etkisi. Doktora Tezi, 2006; Ege Üniversitesi, İzmir. https://acikerisim.ege.edu. tr/xmlui/bitstream/handle/11454/2307/ozlembilik2006. pdf? sequence $=1$ \&isAllowed $=y$

5. Branson JJ, Goldstein WM. Primary total hip arthroplasty. AORN J 2003;78(6):946-74. Crossref

6. Gammon J, Mulholland A. Effect of preparatory information prior to elective total hip replacement on psychological coping outcomes. J Adv Nurs 1996;24(2):303-8. Crossref

7. Roper N, Logan W, Tierney A. The Model of Living, RoperLogan-Tierney Model of Nursing: Based on Activities of Living. UK: Churchill Livingstone; 2000.

8. Altizer L. Patient education for total hip or knee replacement. Orthop Nurs 2004;23(4):283-8. Crossref

9. Petersson I, Lilja M, Hammel J, Kottorp A. Impact of home modification services on ability in everyday life for people ageing with disabilities. J Rehabil Med 2008;40(4):253-60. Crossref

10. Erler K, Demiralp B, Özdemir MT, Bozkurt M. Total Femur Rezeksiyonu ve Prostetik Replasmanın Başarılı Sonuçları: Iki Olgu Sunumu. Acta Orthop Traumatol Turc 2004;38(1):79-84. https://app.trdizin.gov.tr/dokuman-goruntule? ext=pdf\&path= CrnWZGRsXTjRjLjWxD978OSUAL2jXitizhVYmCxNvH4Fb5Hq b09bLw-5rLGQiysWioLijcTI2LvwcKR2f6jJTDkE7Je3WtnSmyug eTUaJA0W3PcCeFw2I1 qkAY_wy-z2m0uuuAXK3rU5O4sJaDjk JJAdCrxaNZcP64WNe1SekWPGTv-yPzVT8Eo05TMLZfXteX5G8 sl5xE4kBYoAjtDGf4KUMoD1x3QsgcJLe16q1c=\&contentType $=$ application/pdf

11. Black JM, Hawks JH. Medical-Surgical Nursing: Clinical Management for Positive Outcomes, 8. ed. Philadelphia: W. B. Saunders Coumpany; 2009.

12. Bilgili N, Akın B, Ege E, Ayaz, S. Kadınlarda Üriner İnkontinans Sıklığı ve Etkileyen Risk Faktörleri. Türkiye Klinikleri J Med Sci 2008;28(4):487-93.

13. Mont MA, Tankersley WS, Hungerford DS. Hip rehabilitation after surgery. In: Young MA, O'Yang B, Steins SA, editors. Rehabilitation secrets. Philadelphia: Hanley and Belfus; 1997. p.330-7.

14. WuJQ, Mao LB, WuJ. Efficacy of exercise for improving functional outcomes for patients undergoing total hip arthroplasty A metaanalysis. Medicine 2019;98(10):e14591. Crossref

15. Swanson EA, Schmalzried TP, Dorey FJ. Activity recommendations after total hip and knee arthroplasty: a survey of the American Association for Hip and Knee Surgeons. J Arthroplasty 2009;24(6 Suppl):120-6. Crossref

16. CreekJ. Occupational therapy defined as a complex intervention. London: College of Occupational Therapists; 2003.

17. Pergolotti M, Williams GR, Campbell C, Munoz LA, Muss HB. Occupational therapy for adults with cancer: Why it matters. Oncologist 2016;21(3):314-9. Crossref

18. Gandhi R, Razak F, Davey JR, Rampersaud YR, Mahomed NN. Effect of sex and living arrangement on the timing and outcome of joint replacement surgery. Can J Surg 2010;53(1):37-41. http://canjsurg.ca/wp-content/uploads/2013/12/53-1-37.pdf

19. Kanan N. Yanıklı Hastanın Evde Bakımı ve Uzun Dönemde Düzelmesi. 1. Ulusal Evde Bakım Kongresi, 1998. İstanbul: Marmara Üniversitesi; 2001. p.159-64.

20. Fielden JM, Gander PH, Horne JG, Lewer BMF, Green RM, Devane PA. An assesment of sleep disturbance in patients before and after total hip arthroplasty. J Arthroplasty 2003;18(3):371-6. Crossref

21. Bitsch M, Foss N, Kristensen B, Kehlet H. Pathogenesis of and management strategies for postoperative delirium after hip fracture: a review. Acta Orthop Scand 2004;75(4):378-89. Crossref 